\title{
Cloning of an Expansin Gene from Chimonanthus praecox Flowers and Its Expression in Flowers Treated with Ethephon or 1-Methylcyclopropene
}

\author{
Jing Ma, Zheng Li, Bin Wang, Shunzhao Sui, and Mingyang Li ${ }^{1}$ \\ Chongqing Engineering Research Center for Floriculture, Key Laboratory \\ of Horticulture Science for Southern Mountainous Regions, Ministry of \\ Education, College of Horticulture and Landscape, Southwest University, \\ Chongqing, 400715, China
}

Additional index words. wintersweet, vase life, 1-methylcyclopropene, real-time PCR, transcript level

\begin{abstract}
Expansins are extracellular proteins that are involved in cell wall modifications such as cell wall disassembly, cell separation, and cell expansion. Little is known about expansin gene expression during flower development of wintersweet (Chimonanthus praecox). In the present study, an expansin gene, $C p E X P 1$, was isolated from the wintersweet flower cDNA library through random sequencing; this gene encodes a putative protein of 257 amino acids with the essential features conserved, like in other alpha expansins. The $C$ PEXP1 gene exhibited different transcription levels in different tissues and had a significantly higher expression in flowers than other tissues. It is strongly correlated with the development of the flower. The expression of $C p E X P 1$ increased in the flower buds or whole flowers from Stage 1 to 4 and decreased from Stage 5 to 6 during natural opening. Ethephon (an ethylene releaser) treatment promoted cut flower senescence, whereas 1-methylcyclopropene (1-MCP) (an ethylene perception inhibitor) delayed the process of flower wilting. This result is associated with the concomitant lower transcript levels of $C p E X P 1$ in the ethephon-treated samples as well as the steady expression in the 1-MCP-treated samples compared with that in control flowers. The studies show the interesting observation that the expression of an expansin gene $C p E X P 1$ is correlated with the development of Chimonanthus praecox flowers, the upregulation during flower opening vs. the downregulation during senescence.
\end{abstract}

Expansin is a cell wall protein, which is a regulatory factor of cell growth. It plays an important role in plant cell wall extension (Lee et al., 2001; Li et al., 2003; McQueenMason et al., 1992). However, the plant cell wall is a complex structure composed of a variety of crosslinked polysaccharides (GonzalezCarranza et al., 2002; Petersen et al., 1995; Zinnia et al., 2007). Various types of cell wall modifier proteins such as expansin protein and other enzymes are involved in the disassembly of the cell wall. Expansins are related to cell growth and cell morphogenesis, fruit softening (Ishimaru et al., 2007; Rose et al., 1997; Trivedi and Nath, 2004), flower organ abscission (Sane et al., 2007), pollination and fecundation, leaf and root hair development, and so on (Cho and Cosgrove, 2002; Fleming

Received for publication 15 May 2012. Accepted for publication 13 Aug. 2012.

This work was supported by the National Natural Science Foundation of China (Grant nos. 31070622 and 30872063), the Fundamental Research Funds for the Central Universities (Grant nos. XDJK2009A004) and the Science \& Technology Innovation Foundation for Postgraduates of Southwest University (Grant nos. kb2009016).

${ }^{1}$ To whom reprint requests should be addressed; e-maillimy@swu.edu.cn. et al., 1997). Expansins constitute a superfamily, and they can be classified into three subfamilies: $\alpha$-expansin, $\beta$-expansin, and expansin-like genes ( $\mathrm{Li}$ et al., 2003). Individual members of the large expansin family in each plant were thought to provide specificity of function in each tissue and may be differentially governed by plant hormones. The relationship between expansins and the development of plant organs has been reported in recent years. A family of expansin transcripts, which includes seven $\alpha$-expansins (MjExp 1-7) and three $\beta$-expansins (MjExpB1-3) from Mirabilis jalapa, showed dramatic changes in transcript abundance during rapid expansion and subsequent senescence of the ephemeral flowers (Gookin et al., 2003). Two expansin genes (DcEXPA1 and DcEXPA2) were found to be associated with petal growth and development during carnation flower opening (Harada et al., 2011). The expression of some $\alpha$-expansin genes is regulated by auxin (Catalá et al., 2000; Hutchison et al., 1999), gibberellin (Azeez et al., 2010; Cho and Kende, 1997; Lee and Kende, 2001), cytokinin (O'Malley and Lynn, 2000; Wrobel and Yoder, 2001), and ethylene (Kim et al., 2000; Sane et al., 2007; Vriezen et al., 2000).

Wintersweet, which blossoms particularly in winter, is one of the important woody cut ornamental flowers with high economic value that thrives in central south and southwest China. The vase life of wintersweet cut flowers consists of the period from flower opening to senescence. Slowing down both processes to prolong the display time of the flowers is becoming an important concern. In the present article, a new expansin gene, $C p E X P 1$, from wintersweet is described. This article characterizes the ethephon responsiveness of the wintersweet flower from opening to senescence and shows that its flower development is closely associated with the expression of a new expansin gene, $C p E X P 1$.

\section{Materials and Methods}

Plant material. The flower opening process was separated into six stages. Stage 1 is the flower-bud period, when flower buds turn green. Stage 2 is the display-petal period, when flower buds enlarge and turn yellow. Stage 3 is the initiating bloom period, when fragrance emerges. Stage 4 is the bloom period, when flowers fully open with strong fragrance. Stage 5 is the early-wither period, when petals begin withering. Stage 6 is the later-wither period (Wu et al., 1995). For gene expression analysis, different tissues (i.e., external petal, middle petal, inner petal, stamen, and pistil) were detached from fully opened flowers at Stage 4, as shown in Figure 1A. Flower buds or flowers of wintersweet, representative of the six stages of the flower process, were collected from the nursery at Southwest University, Chongqing, China, as shown in Figure 1B. Additional tissues such as cotyledons were still emerging from beneath the seedcoat. Root, stem, and young expanding leaves were collected from the six-leaf stage young plant. Mature leaves were collected from a wintersweet adult plant. All samples were picked and immediately frozen with liquid nitrogen and then stored in a refrigerator at $-80{ }^{\circ} \mathrm{C}$ until RNA isolation.

cDNA synthesis was performed from mixed wintersweet flowers across the six development stages. Total RNA and library construction through directional cloning of cDNAs into the $\lambda$ TriplEx 2 vector were performed using the SMART cDNA Library Construction Kit. A total of 867 random cDNA clones were successfully sequenced to generate high-quality expressed sequence tags (ESTs) (Sui et al., 2012).

Ethephon and 1-methylcyclopropene treatment and vase life statistics. Flowering branches, containing $\approx 38$ to 40 flower buds at Stage 2, were cut using a sharp blade and immediately enclosed in an airtight chamber that contains either water (as control) or ethephon (an ethylene releaser) $\left(200 \mathrm{mg} \cdot \mathrm{L}^{-1}\right)$, and the ethylene inhibitor was $1-\mathrm{MCP}\left(1 \mu \mathrm{l} \cdot \mathrm{L}^{-1}\right)$. The flower buds on the same branch do not show similar morphologies. They could not range within the same opening level on the same day. Thus, we collected flower buds or flower samples for RNA isolation when over $50 \%$ of the flowers on the same branch ranged within the same development level. The opening and wilted rates were recorded daily. The five outermost petals were detached from 10 flowers 
at different flower opening of Stages 4 to 6 (all treatments), mixed (a sample of 50 petals), and immediately frozen in liquid nitrogen for RNA extraction. Vase life was defined as the total days from the first day of vase holding to the day when more than $50 \%$ of wintersweet flowers on the branch wilted and lost ornamental value. Meanwhile, the flowering and wilting rates were calculated daily. The flowering and wilting rates were defined according to the following formulas, and studies were carried out on three independent branches for each treatment.

percentage of open flowers $(\%)=$

the total number of bloomed

flowers on test-day

the total number of initial flower $* 100 \%$

buds on the branch

percentage of wilted flowers $(\%)=$

the total number of wilting flowers and abscission flower

buds on test-day

the total number of initial flower $* 100 \%$

buds on the branch

Isolation of RNA. Total RNA was extracted from different samples, as described earlier, using the RNAprep pure Plant RNA Kit (TIANGEN, Beijing, China) according to the manufacturer's instructions. RNA quality was detected using Bio-specmini (Shimadzu, Kyoto, Japan).

Cloning of expansin cDNA and sequence analysis. Through a random selection of clones from the library and bidirectional sequencing with the $5^{\prime}$ pTriplEx 2 sequence primer $\left(5^{\prime}-\mathrm{TC}\right.$ CGAGATCTGGACGAGC-3') from the $5^{\prime}$ end using ABI 3700 (Applied Biosystems, CA), potential target EST sequences were isolated. After cluster analysis and multiple alignments using SeqMan and BLAST software, the SP5 (5'-CTTCTGCTCTAAAAGCTGCG-3') and T7 (5'-TAATACGACTCACTATAGGG-3') were taken as sequencing primers for the forward and backward sequencings to isolate the full-length cDNA of the target clone from the library. The corresponding genomic DNA sequence was cloned using the cDNA sequence (forward primer CpEXP1-F: 5'-TTCGCTTT GGCATTG-3' and reverse primer CpEXP1-R: 5'-AACATATTGGGATCTCCT-3') to analyze the existence of an intron within the genomic region. DNAStar5.0 and BLASTX comparisons were used with an ORF finder, multiple alignment, and phylogenetic tree construction.

Real-time polymerase chain reaction analysis. Equal amounts of DNA-free RNA $(5 \mu \mathrm{g})$ from different tissues were reversetranscribed using the PrimeScript RT Reagent Kit with gDNA Eraser (TaKaRa, Otsu, Japan). Real-time polymerase chain reaction (PCR) was performed in triplicate on $10-\mu \mathrm{L}$ reactions using $5 \mu \mathrm{L}$ of Ssofast EvaGreen Supermix (Bio-Rad, Hercules, CA), $0.5 \mu \mathrm{L}$ of each primer (500 $\mathrm{nM}$ final concentration),

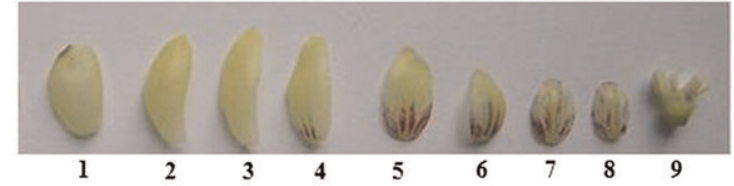

1-3: external petal; 4-5:middle petal; 6-8:inner petal; 9:stamen and pistil

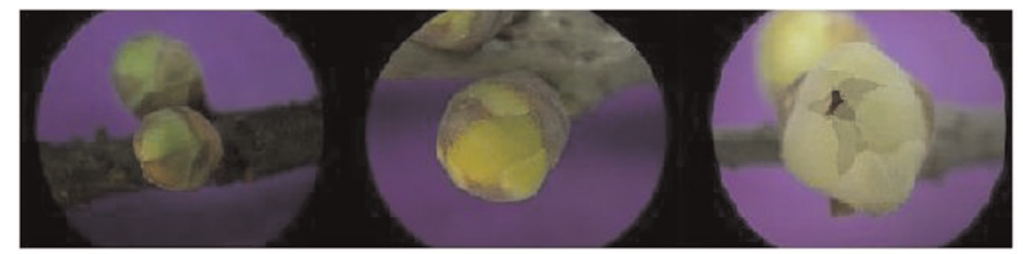

stage 1

stage 2

stage 3

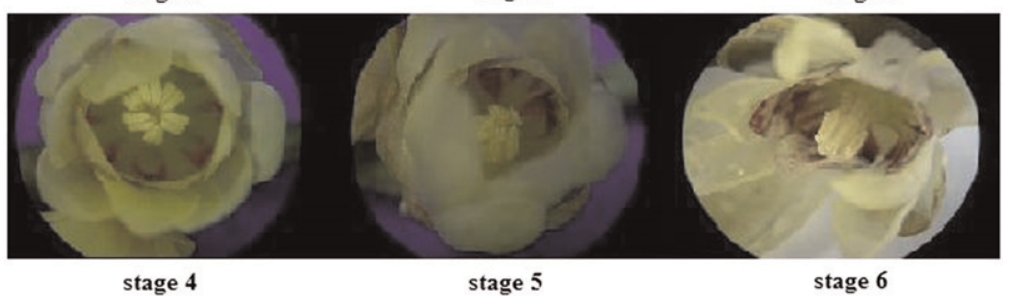

Fig. 1. Floral tissues of bloomed single flower (A) and different stages of wintersweet flower development (B).

Table 1. Primers used for real-time polymerase chain reaction amplifications.

\begin{tabular}{lll}
\hline Gene name & Primer name & \multicolumn{1}{c}{ Primer sequence $\left(5^{\prime}-3^{\prime}\right)$} \\
\hline CpEXP1 & q-CpEXP2F & GCAAGAAACAAGGAGGAGTAAG \\
Actin & q-CpEXP2R & CCATCCATCCAGTCTTTGAACC \\
Tublin & ActinF & AGGCTAAGATTCAAGACAAGG \\
& ActinR & TTGGTCGCAGCTGATTGCTGTG \\
& TublinF & GTGCATCTCTATCCACATCG \\
& TublinR & CAAGCTTCCTTATGCGATCC \\
\hline
\end{tabular}

$3.5 \mu \mathrm{L}$ water, and $0.5 \mu \mathrm{L}$ cDNA template. Primers (Table 1) for the real-time PCR were designed by Primer Premier 5.0 (PREMIER Biosoft, Palo Alto, CA). PCR was carried out using the Bio-Rad CFX96 (Bio-Rad) realtime system machine, following the manufacturer's instructions, using a denaturation temperature of $95^{\circ} \mathrm{C}$ for $30 \mathrm{~s}$ followed by 40 cycles of $95{ }^{\circ} \mathrm{C}$ for $5 \mathrm{~s}$ and $58{ }^{\circ} \mathrm{C}$ for $5 \mathrm{~s}$. To control the specificity of the annealing of the oligonucleotides, dissociation kinetics were performed using the real-time PCR system at the end of the experiment (60 to $95{ }^{\circ} \mathrm{C}$, continuous fluorescence measurement). A comparative $\mathrm{Ct}$ method $\left(2^{-\Delta \Delta \mathrm{Ct}}\right)$ of relative quantification (Livak and Schmittgen, 2001) was used to analyze the real-time quantitative PCR data using Bio-Rad CFX Manager Software Version 1.6. The genes for actin and tubulin (Sui et al., 2012) were used for the calculation of the relative transcript abundance. The sizes of the amplified products were confirmed through gel electrophoresis. Negative controls without templates were concurrently carried out.

\section{Results and Discussion}

Isolation of expansin gene and sequence characterization. Expansin is an important part of the plant cell wall, and its main role is to loosen the components of the plant cell wall and to increase the flexibility of the cell wall. These roles determine its participation in the activities of many plant cell processes such as the development of root, stem, leaf, flower, fruit, and seed (Fagard et al., 2000; Martin et al., 2001; Smith, 2003). An expansin gene was isolated from the wintersweet flower cDNA library through random clone selection and sequencing. The complete cDNA was $1115 \mathrm{bp}$ long and contained an open reading frame of $771 \mathrm{bp}$ and a $3^{\prime}$-UTR of $260 \mathrm{bp}$. There were two introns of 85 and $316 \mathrm{bp}$ in the expansin gene, which were revealed by a comparison of cDNA and genomic DNA sequences. In the conserved intron mode of the expansin gene family, most of the $\alpha$-expansin gene had two introns belonging to intron 1 and intron 3, respectively. The gene, designated as $C p E X P 1$ (GeneBank accession number: JN700522), encoded a putative protein of 257 amino acids with a molecular mass of $27.7 \mathrm{kDa}$ and an isoelectric point of 7.8. The common features of the $\alpha$-expansin subfamily such as eight conserved cysteine residues overall, four conserved tryptophan residues at the C-terminus, and a conserved HFD motif (family-45 internal glucosylase domain) were conserved in the deduced protein. The CpEXP1 protein also included a signal peptide of which the cleavage site was predicted to be at amino acid number 24 . This signal peptide probably targets the protein to the cell walls, and this has been shown to be present in other members of the alpha-expansin families in 
other plants, as shown in Figure 2A. The phylogenetic analysis of the predicted protein through CLUSTAL W showed that it was closest to the $\alpha$-expansin RcEXP11 from Ricinus communis. The predicted protein appeared to be closer to the expansins from Glycine max and Malus hupehensis and to the alpha-expansins from Arabidopsis thaliana and Arabidopsis lyrata subsp. However, Arabidopsis lyrata subsp. was distinct from the expansion-related expansins of Zea mays, Triticum aestivum, and Festuca pratensis, as shown in Figure 2B.

A

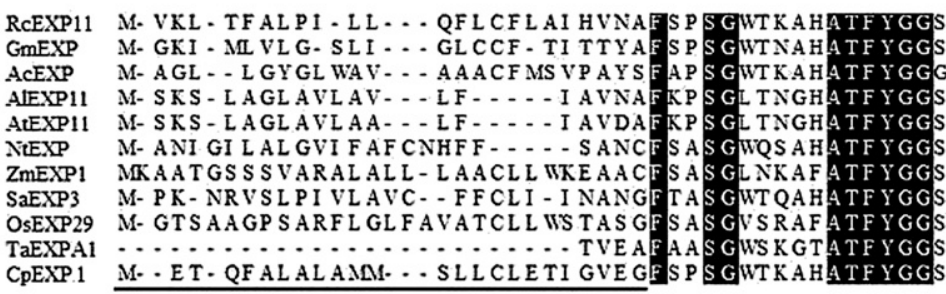

RCEXP11 I MCDY QTDP R WC

GmEXP II DYKSDSRWCI

I I DSNADP R WCL KGKSVTVTA TNFCP P NF GL P NNGG WC NP PLQHF DMAQPA WE QI AI

I TCDYAADSR WCLKGASVVI TATNFCP P NF AL P NNNGGWCNP P L KHF DMAQPA WE KI GI

AEXPII I TCDHAADSRWCL KGASVVI TATNFCP P NFAL PNNGGWCNPP L KHF DMAQPA WE KI GI

NEXPP I MCDYNQDPKWCRKGTYVTI TATNF C P P NYALP SNNGGWCNP PRPHF DMAQPA WE NI GI

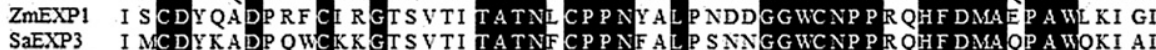

OsEXP29 I RCDYAADPRFCI RGASVTI TATNLCP P NYALP NDDGGWCNP PRQHF DMAEPAWL NI GV

TaEXPA1 I TCDARADP R WCRAGAS VTVTATNF C P NYAL P DDGGWCNP PR PHF DMAQPAWERI GV

CPEXP1 II CDYQSDP KWCL KGTSVTITATNFCP PNFALSNNGGWCNP PL QHF DMAQPAWE KL GF CDYQSDPKWCA $\uparrow$

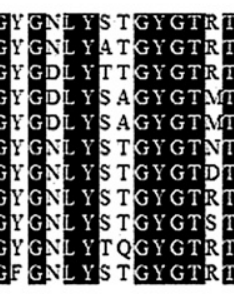

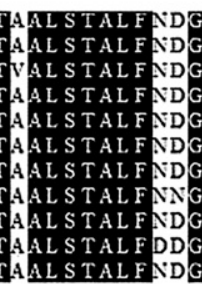

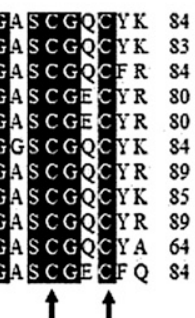

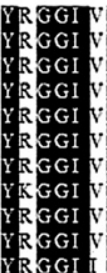

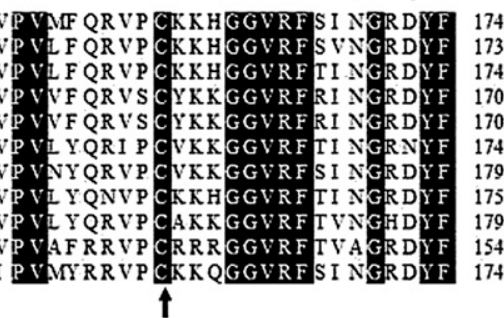

RcEXP11 EIVLI SNVAGAGSI QSVSI KGSK - TGMMAMSRNWGANWQSNS YLNGQSLSFIKITTTDGATRFFPNVVPSNMAFGQTFSS SVQ- F

GMEXP ELVLI SNVGGAGSI QSVFI KGSK. TGWMAMSRNWG NWOSAAYL NGQSLSFRVTTTDGETRVFODI VPVSWTFGQTFSSPVOF

GIENPP

AcEXP

AIEXP11 ELVNI QNVGGAGSI KSVSIKGS

AtEXPII EIVNI QNVGGAGSI KSVSI K

NUEXP ELLII SNVGGAGSVQSVQI K

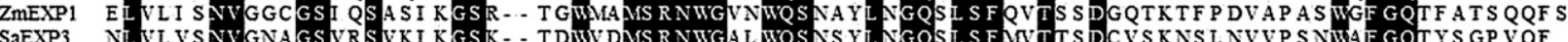

作

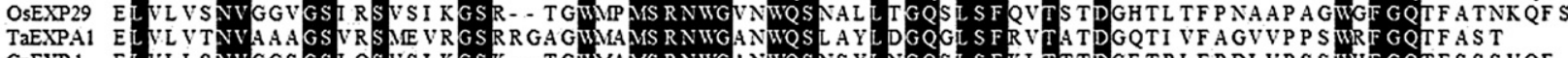

CPEXP1 ELVLI SNVGGSGSI QSVSI KGSK- T TWMAMSRNWGANWOSNS YLNGQSLSFI TTTDGETRLFPDI VPS SWHF GQTFSSS VQF

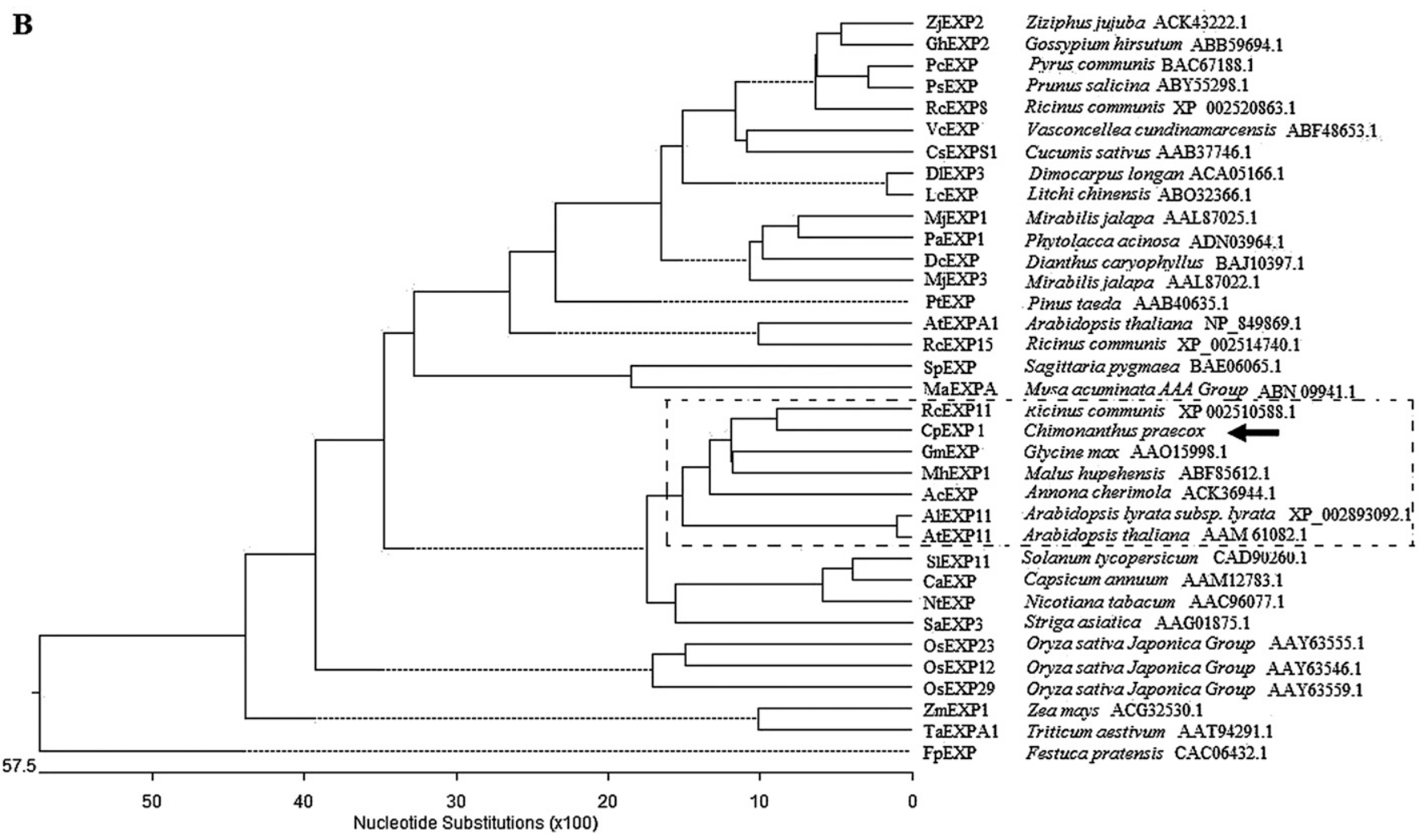

Fig. 2. Alignment of deduced full-length amino acid sequence (A) and phylogenetic tree $(\mathbf{B})$ of CpEXP1 protein. Identical and similar amino acids are represented by a black box. The putative signal peptide is underlined. We use the conserved cysteines (C), tryptophans (W), and the HFD motif, which were indicated with arrow symbols, triangle symbols, and double underline, respectively, as the key signatures of the expansin family. Multiple alignments were done through ClustalW using the MegAlign program (DNASTAR, Madison, WI). The tree was generated using the MegAlign program in DNAStar with the ClustalW method and PAM250 residue weight table. The position of $C p E X P 1$ in the tree is indicated by an arrow. The group of expansins closely related to $C p E X P 1$ is boxed with a dotted line. The GeneBank accession numbers were marked followed by the protein name in the phylogenetic tree. 
Expression analysis of expansin gene in different tissues. Expansins are known to belong to a multigene family of proteins and have been demonstrated to have organ-specific ( $\mathrm{Wu}$ et al., 2001), tissue-specific (Chen and Bradford, 2000), and cell-specific (Im et al., 2000) expression patterns. The $C p E X P 1$ gene exhibits different expression levels in each phase of the wintersweet flower, as shown in Figure 3A. In the bloomed flower, the expression of $C p E X P 1$ gradually increased from the exterior to the interior and reached the maximum at the inner petal. The expression was higher in the reproductive organ than in the petal. The stamen had maximum expression among all the flower organs detected, which was nearly 70 -fold that in the cotyledon. The present study was extended to include other tissues such as root, stem, and leaf. In the leaves, the CpEXP1 expression in the mature leaves was higher than that in the cotyledon and young leaves, which was different from the gladiolus $G g E X P A 1$ that is expressed in young growing/expanding leaves but is not observed in mature leaves (Azeez et al., 2010). The expression of the CpEXPI gene was barely detectable in the cotyledon and young leaves. A very low expression was also observed in the root and stem compared with the Stage 4 whole flower, as shown in Figure 3A.

Expression analyses during flower opening and senescence. Expansins are believed to be important in cell wall extension and modification. Their functions are likely to affect flower development. Although expansin genes are shown to be expressed in floral primordial (Reinhardt et al., 1998) and mature floral tissues (Michael, 1996), few comprehensive reports on the study of expansins in relation to flower bloom and senescence are available. In the present article, total RNA was isolated from flower buds and whole flowers at different stages to study the expression pattern of the gene during flower growth and senescence in wintersweets. The $C p E X P 1$ expression was shown to be directly related to the development of wintersweet flowers. The results of real-time PCR detection showed that the transcript levels of the CpEXP1 gene in the flower buds gradually increased in the early stages of flower development from Stage 1 to Stage 4 and presented a peak at Stage 4 . The transcript levels of the gene showed a drastic reduction in Stage 5 and then decreased further in the following stages, as shown in Figure 3B. The increased expression of the gene can be seen in the flower buds in the early developing/expanding stages. The increase, compared with that in bud development, indicated that the gene is an expansion-related gene. Similar to gladiolus GgEXPA1 (Azeez et al., 2010), the expression of $C P E X P 1$ decreased after the flowering stages (Stages 5 to 6) with the process from bloom to senescence. Stage 4 is the bloomed period; the petal area did not increase any more after this stage, as shown in Table 2. The high expression of the CpEXP1 gene may be one of the reasons that the flower buds easily fall at this stage. After the cessation of expansion from Stage 4 onward, the flowers wilted and gradually became senescent.

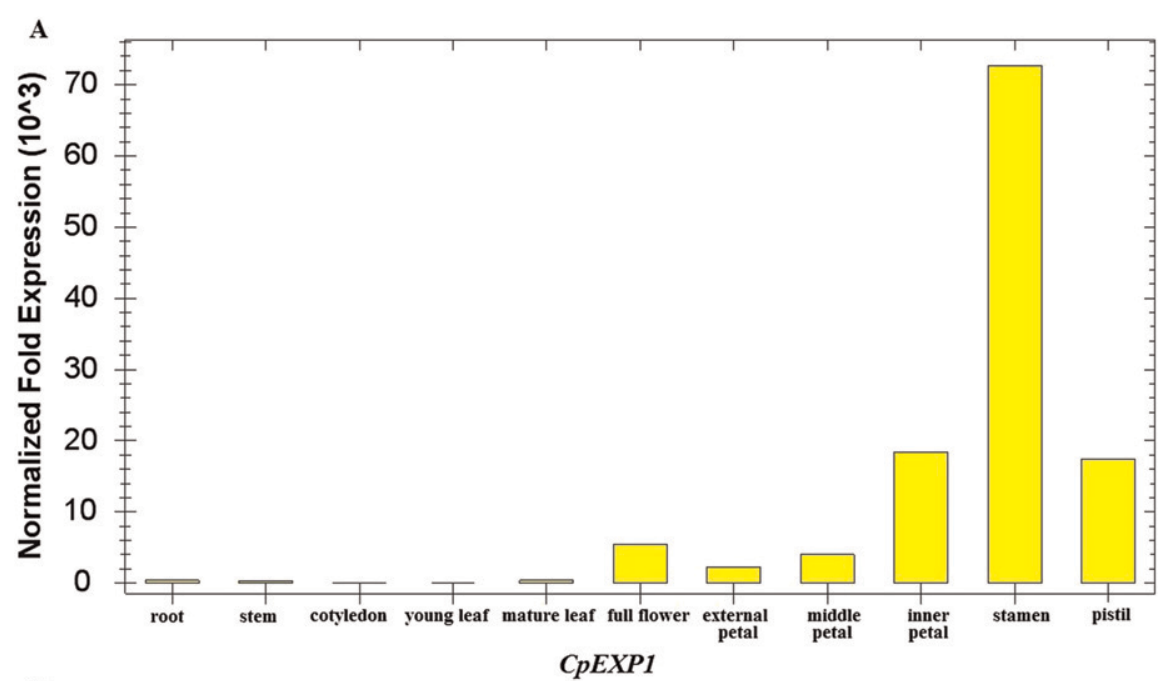

B

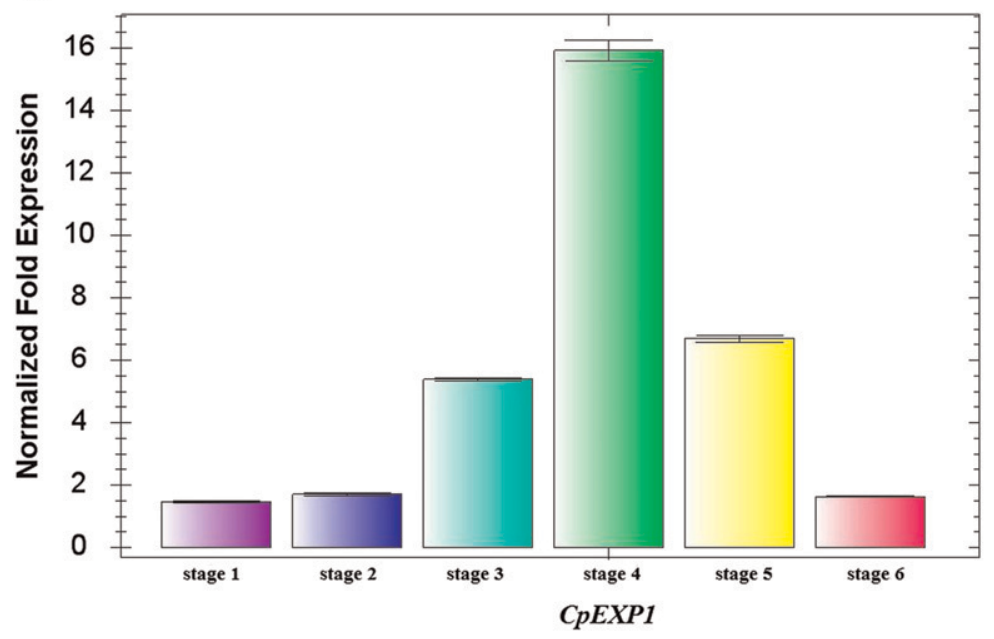

Fig. 3. Real-time quantitative polymerase chain reaction (PCR) analyses of transcript levels in different tissues $(\mathbf{A})$ and during the development stages of the flowers $(\mathbf{B})$. Cotyledons were still emerging from beneath the seedcoat. Root, stem, and young leaves were collected from the six-leaf stage young plant. Mature leaves were collected from the wintersweet adult plant (Stage 4). Data were normalized against a reference of the wintersweet actin and tublin genes. For each cDNA sample, $\mathrm{n}=3$ determinations were made through real-time PCR, and the error bars indicate SD. The flower buds from Stages 1 to 3 and the whole flowers from Stages 4 to 6 were used for real-time PCR analysis of gene expression during the development stages of the flowers.

Table 2. Petal area of different petals from Stage 3 to 6.

\begin{tabular}{lcccc}
\hline & Stage 3 & Stage 4 & Stage 5 & Stage 6 \\
\hline External petal $\left(\mathrm{mm}^{2}\right)$ & $92.05 \pm 1.90 \mathrm{~b}$ & $98.04 \pm 2.32 \mathrm{ab}$ & $98.01 \pm 2.19 \mathrm{ab}$ & $95.13 \pm 1.57 \mathrm{a}$ \\
Middle petal $\left(\mathrm{mm}^{2}\right)$ & $51.45 \pm 1.25 \mathrm{a}$ & $55.22 \pm 1.07 \mathrm{ab}$ & $55.26 \pm 1.02 \mathrm{~b}$ & $51.35 \pm 0.87 \mathrm{~b}$ \\
Inner petal $\left(\mathrm{mm}^{2}\right)$ & $12.58 \pm 0.63 \mathrm{~b}$ & $16.26 \pm 0.27 \mathrm{a}$ & $16.30 \pm 0.34 \mathrm{a}$ & $12.18 \pm 0.15 \mathrm{ab}$ \\
\hline
\end{tabular}

The petal area was measured by LI-3100C leaf area meter and 20 petals of each stage were measured. The data were represented as a result of means $\pm \mathrm{SD}(\mathrm{a}, \mathrm{b})(P<0.05)$.

Effect of ethephon and 1-methylcyclopropene on cut flower vase life. Previous research suggests that wintersweet cut flowers lack the capability for ethylene production and that they are insensitive to ethylene. Thus, the flower must be the non-climacteric ethylene type and insensitive ethylene type (Sheng et al., 1999). In our study, however, the cut flower showed a marked response to ethephon. To study the effect of exogenous ethephon and 1-MCP on flower opening and senescence, we treated the flower branches of Stage 2 with ethephon and 1-MCP, because the flowers at this stage are under blossom, which is beneficial for observing the entire process of the flower development. The two different treatments showed varying flowering rates, wilting rates, and vase lives compared with those of the control cut flowers. The senescence of the wintersweet cut flower contained two main forms, including wilt and abscission after wilting for 1 week, whereas abscission without wilt was uncommon. As shown in Figure $4 \mathrm{~A}$, in the first $3 \mathrm{~d}$ of the vase life test, the flowering of the ethephon and 1-MCPtreated samples were all lower than those of 
the control samples, whereas the ethephontreated and the control samples reached maximum flowering on the third day. Afterward, the ethephon treatment accelerated the process of flower opening, resulting in higher flowering compared with the control flowers during the succeeding opening days (Stages 2 to 4). In contrast, the 1-MCP treatment could delay blooming; wintersweet reached maximum flowering on the fourth day. On the other hand, with the opening of new buds, the flowers treated with ethephon and water began to decline from the third day, whereas the 1-MCP treatment delayed the trend of flower wilting, as shown in Figure 4B. This result indicates that flower senescence in wintersweet is sensitive to ethephon and can be delayed with 1-MCP. The 1-MCP treatment prolonged vase life of cut flowers to $16 \mathrm{~d}$ compared with the $11 \mathrm{~d}$ of the control flowers and the $9 \mathrm{~d}$ of the ethephon-treated samples.

Effect of ethephon and 1-methylcyclopropene on CpEXP1 expression. To study the expression pattern of the expansin gene affected by ethephon and 1-MCP during wintersweet flower opening and wilting, real-time PCR was performed to detect the transcript level of the $C p E X P 1$ at different opening stages. As shown in Figure $4 \mathrm{C}$, a decrease in the steady state level of the $C p E X P 1$ transcript in the petals was detected at Stage 3 of exogenous ethephon application and continued until Stage 6 , thus correlating it with the progression of senescence. Ethephon treatment promoted cut flower senescence, whereas 1-MCP delayed the process of flower wilting. Thus, the role of ethephon in the progression of flower senescence is proven. Stage 4 can be seen as the separatrix of flower development. During the early opening stage of the wintersweet flower before Stage 4, ethephon treatment raised the flowering ratio, and 1-MCP had an insignificant effect on flowering. This result is associated with the concomitant lower transcript levels of $C p E X P 1$ in the ethephontreated samples as well as the steady expression in the 1-MCP-treated samples compared with that in control flowers. After Stage 4, the cut flowers began to decline. The wilting rates shown in Figure 4B reveal a completely different response model between the different treatments (ethephon and 1-MCP) and the control. In conclusion, cut flower early opening in wintersweet appears to be associated with the low expression level of an ethephonresponsive $\alpha$-expansin gene, CpEXP1. The delay in cut flower senescence may be associated with the enhanced expression of $C p E X P 1$.

In conclusion, $C p E X P 1$ provides a example of an expansin gene involved in flower development. The CPEXP1 had the maximum expression in the stamen of the bloomed flower at Stage 4 and hardly any leaf related expression was observed. The expression of the CpEXP1 in the wintersweet increased at first and then decreased during the whole flower development process. In this article, we provide the first evidence for transcriptional downregulation of the expansin gene during the progression of flower opening and wilting in wintersweet after the ethephon treatment of cut flowers.
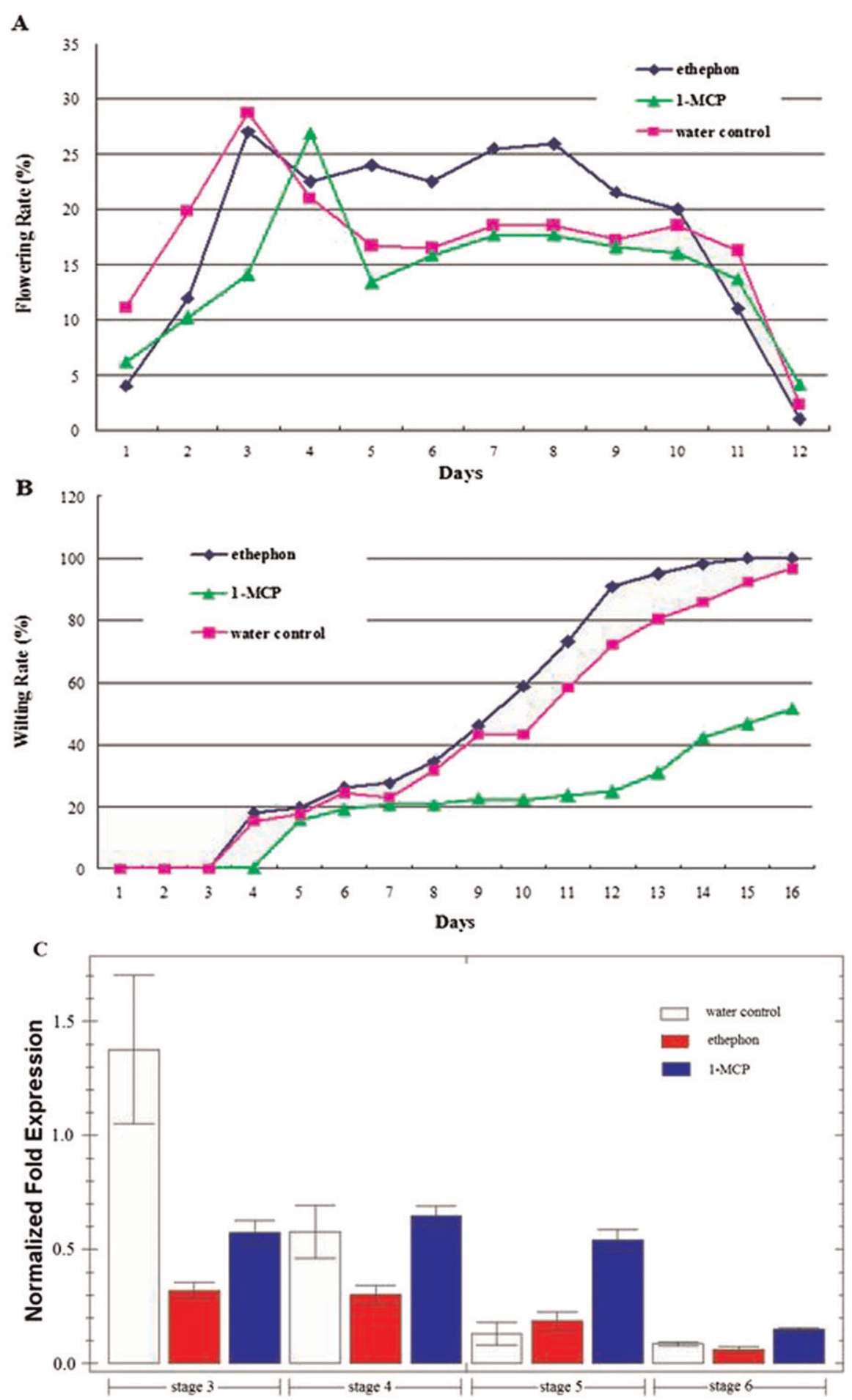

Fig. 4. Changes in flowering rate (A), wilting rate (B), and $C p E X P 1$ transcript accumulation in petals of wintersweet flowers treated with ethephon or 1-methylcyclopropene (1-MCP) (C). Flower branches at Stage 2 were cut and divided into three lots: untreated (water control), treated with $1 \mu 1 \cdot \mathrm{L}^{-1} 1-\mathrm{MCP}$, and treated with $200 \mathrm{mg} \cdot \mathrm{L}^{-1}$ ethephon. The flowering and wilting rates were analyzed everyday. The five outermost petals were detached from ten flowers at different flower opening Stages 3 to 6 (all treatments and control), mixed (a sample of 50 petals), and immediately frozen in liquid nitrogen for extraction of RNA. The relative gene expression levels of the CPEXPI gene are shown after normalization with actin and tublin gene transcript values. Values and error bars are the average and the SD from three independent biological repetitions and three repeated measurements through realtime PCR.

\section{Literature Cited}

Azeez, A., A.P. Sane, S.K. Tripathi, D. Bhatnagar, and P. Nath. 2010. The gladiolus GgEXPA1 is a GA-responsive alpha-expansin gene expressed ubiquitously during expansion of all floral tissues and leaves but repressed during organ senescence. Postharvest Biol. Technol. 58:48-56.

Catalá, C., J.K.C. Rose, and A.B. Bennett. 2000. Auxinregulated genes encoding cell wall-modifying 
proteins are expressed during early tomato fruit growth. Plant Physiol. 122:527-534.

Chen, F. and K.J. Bradford. 2000. Expression of an expansin is associated with endosperm weakening during tomato seed germination. Plant Physiol. Biochem. 124:1265-1274.

Cho, H.T. and D.J. Cosgrove. 2002. Regulation of root hair initiation and expansin gene expression in Arabidopsis thaliana. Plant Cell 14:32373253.

Cho, H.T. and H. Kende. 1997. Expression of expansin genes is correlated with growth in deepwater rice. Plant Cell 9:1661-1671.

Fagard, M., T. Desons, T. Desprez, F. Goubet, G. Refregier, G. Mouille, M. Mccann, C. Rayon, S. Vernhettes, and H. Hofte. 2000. PROCUSTE1 encodes a cellulose synthase required for normal cell elongation specifically in roots and dark-grown hypocotyls of Arabidopsis thaliana. Plant Cell 12:2409-2424.

Fleming, A.J., S. McQueen-Mason, T. Mandel, and C. Kuhlemeier. 1997. Induction of leaf primordia by the cell wall protein expansin. Science 276:1415-1418.

Gonzalez-Carranza, Z.H., C.A. Whitelaw, R. Swarup, and J.A. Roberts. 2002. Temporal and spatial expression of a polygalacturonase during leaf and flower abscission in Brassica napus and Arabidopsis thaliana. Plant Physiol. 128:534-543.

Gookin, T.E., D.A. Hunter, and M.S. Reid. 2003. Temporal analysis of alpha and beta-expansin expression during floral opening and senescence. Plant Sci. 164:769-781.

Harada, T., Y. Torii, S. Morita, R. Onodera, Y. Hara, R. Yokoyama, K. Nishitani, and S. Satoh. 2011. Cloning, characterization, and expression of xyloglucan endotransglucosylase/hydrolase and expansin genes associated with petal growth and development during carnation flower opening. J. Expt. Bot. 62:815-823.

Hutchison, K.W., P.B. Singer, S. Mcinnis, C. DiazSala, and M.S. Greenwood. 1999. Expansins are conserved in conifers and expressed in hypocotylsin response to exogenous auxin. Plant Physiol. 120:827-831.

Im, K.H., D.J. Cosgrove, and A.M. Jones. 2000. Subcellular localization of expansin mRNA in xylem cells. Plant Physiol. 123:463-470.

Ishimaru, M., D.L. Smith, K.C. Gross, and S. Kobayashi. 2007. Expression of three expansin genes during development and maturation of
Kyoho grape berries. J. Plant Physiol. 164:16751682.

Kim, J.H., H.T. Cho, and H. Kende. 2000. $\alpha$-Expansins in the semiaquatic ferns Marsilea quadrifolia and Regnellidium diphyllum: Evolutionary aspects and physiological role in rachis elongation. Planta 212:85-92.

Lee, Y., D. Choi, and H. Kende. 2001. Expansins: Ever-expanding numbers and functions. Curr. Opin. Plant Biol. 4:527-532.

Lee, Y. and H. Kende. 2001. Expression of $\beta$-expansins is correlated with elongation of internodes in deepwater rice. Plant Physiol. 127:645-654.

Li, Y., L. Jones, and S.J. McQueen-Mason. 2003. Expansins and cell growth. Curr. Opin. Plant Biol. 6:603-610.

Livak, K.J. and T.D. Schmittgen. 2001. Analysis of relative gene expression data using real-time quantitative PCR and the $2^{-\Delta \Delta C t}$ method. Methods 25:402-408.

Martin, C., K. Bhatt, and K. Baumann. 2001. Shaping in plant cells. Curr. Opin. Plant Biol. 4:540-549.

McQueen-Mason, S.J., D.M. Durachko, and D.J. Cosgrave. 1992. Two endogenous proteins that induce cell-wall extension in plants. Plant Cell 4:1425-1433.

Michael, A.J. 1996. A cDNA from pea petals with sequence similarity to pollen allergen, cytokinin-induced and genetic tumour-specific genes: Identification of a new family of related sequences. Plant Mol. Biol. 30:219-224.

O'Malley, R.C. and D.G. Lynn. 2000. Expansin message regulation in parasitic angiosperms: Marking time in development. Plant Cell 12: 1455-1465.

Petersen, M., L. Sander, R. Child, O.H. Van, P. Ulvskov, and B. Borkhardt. 1995. Isolation and characterization of a pod dehiscence zonespecific polygalacturonase from Brassica napus. Plant Mol. Biol. 31:517-527.

Reinhardt, D., F. Wittwer, T. Mandel, and C. Kuhlemeier. 1998. Localized upregulation of a new expansin gene predicts the site of leaf formation in the tomato meristem. Plant Cell 10:1427-1437.

Rose, J.K.C., H.H. Lee, and A.B. Bennett. 1997. Expression of a divergent expansin gene is fruit-specific and ripening-regulated. Proc. Natl. Acad. Sci. USA 94:5955-5960.
Sane, A.P., S.K. Tripathi, and P. Nath. 2007. Petal abscission in rose (Rosa bourboniana var Gruss an Teplitz) is associated with the enhanced expression of an alpha expansin gene, RbEXPA1. Plant Sci. 172:481-487.

Sheng, A.W., W.M. Guo, and Z.H. Sunday. 1999. Study on dynamics of endogenous hormones and parameters concerned senescence in cut wintersweet flowers. J. Beijing For. Univ. 2:48-53.

Smith, L.G. 2003. Cytoskeletal control of plant cell shape: Getting the fine points. Curr. Opin. Plant Biol. 6:63-73.

Sui, S.Z., J.H. Luo, J. Ma, Q.L. Zhu, X.H. Lei, and M.Y. Li. 2012. Generation and analysis of expressed sequence tags from Chimonanthus praecox (Wintersweet) flowers for discovering stress-responsive and floral development-related genes. Comp Funct Genomics. doi: 10.1155/2012/ 134596.

Trivedi, P.K. and P. Nath. 2004. MaExp1, an ethylene-induced expansin from ripening banana fruit. Plant Sci. 167:1351-1358.

Vernhettes, S. and H. Hofte. 2002. KOBITO1 encodes a novel plasma membrane protein necessary for normal synthesis of cellulose during cell expansion in Arabidopsis thaliana. Plant Cell 14:2001-2013.

Vriezen, W.H., B. De Graaf, C. Mariani, and LACJ Voesenek. 2000. Submergence induces expansin gene expression in flooding-tolerant Rumex palustris and not in flooding-intolerant R. acetosa. Planta 210:956-963.

Wrobel, R.L. and J.I. Yoder. 2001. Differential RNA expression of $\alpha$-expansin gene family members in the parasitic angiosperm Triphysaria versicolor (Scrophulariaceae). Gene 266:8593.

Wu, C.L. and N.Z. Hu. 1995. Studies on the flower form and blooming characteristics of the wintersweet. Acta Horticulturae Sinica. 22:277282.

Wu, Y., R.B. Meeley, and D.J. Cosgrove. 2001. Analysis and expression of the alpha-expansin and beta-expansin gene families in maize. Plant Physiol. 126:222-232.

Zinnia, H., Z.H. Gonzalez-Carranza, and J.A. Roberts. 2007. Expression of polygalacturonases and evidence to support their role during cell separation processes in Arabidopsis thaliana. J. Expt. Bot. 58:3719-3730. 